\title{
Thermogravimetry applied to characterization of fly ash-based MCM-41 mesoporous materials
}

\author{
Izabela Majchrzak-Kucęba
}

Received: 24 February 2011 / Accepted: 2 September 2011/Published online: 18 September 2011

(C) The Author(s) 2011. This article is published with open access at Springerlink.com

\begin{abstract}
The thermogravimetry (TG) was used for characterization of the fly ash (FA)-based MCM-41 mesoporous materials. MCM-41 mesoporous materials were synthesized using silica extracts from different FA. The synthesis of MCM-41 from FA was carried out by the hydrothermal method using the supernatants of coal FA (in the form of sodium silicate) and cationic cetyltrimethylammonium bromide (CTAB) surfactants as the structuredirecting agents. On the basis of the data obtained from the TG analysis, thermal behaviour of FA-based MCM-41 mesoporous materials was assessed. This study has established the range of temperatures corresponding to the desorption of water, decomposition of the surfactant and condensation of silanol, thereby making the overall quality assessment of FA-based MCM-41 mesoporous materials.
\end{abstract}

Keywords Thermogravimetry - MCM-41 · Fly ash · Thermal behaviour

\section{Introduction}

Studies on the modification of fly ashes (FA), which have been carried out in recent years, have confirmed the possibility of obtaining on their basis microporous materialszeolites with very good ion-exchange and sorption properties $[1,2]$. This fact encouraged searches for new possibilities of using FA as a source of silicon and aluminium. The synthesis

I. Majchrzak-Kucęba ( $\square)$

Faculty of Engineering and Environmental Protection,

Czestochowa University of Technology, Ul. Dąbrowskiego 73,

42-200 Częstochowa, Poland

e-mail: izak@is.pcz.czest.pl of FA-based mesoporous materials, the information of which can be found in references [3-8], has turned out to be one of those possibilities. Although porous solid bodies (containing micro-, meso- and macropores) are a group of materials being widely used in catalytic, purification and separation processes for a long time, the synthesis of materials containing mesopores of uniform size fructified into a success only in 1992, when scientists of the Mobil Company discovered a family of materials designated with the symbol M41S [9]. Though many types of mesoporous materials are known as of now, their large-scale production is limited for both environmental and economical reasons (the cost and toxicity of templates used in the synthesis and the sources of silicon (sodium silicate and tetraethyl orthosilicate). In view of these data, a concept which appears to be interesting is that of utilizing FA as a cheaper source of silicon for the industrial scale production of mesoporous materials on its basis. FA are waste products of coal combustion in a coal-fired power station (in high temperature conditions) and have mostly low surface area. Converting waste products into low-cost mesoporous materials with developed porous structure has important economical and environmental implications. Although the porous structure parameters and other FA mesoporous material properties are slightly inferior to commercial materials, yet they can be successfully used in many applications, e.g., as gaseous pollutant adsorbents. An example in this case may be the removal of $\mathrm{CO}_{2}$ from flue gases $[10,11]$. It is of special importance due to the overall world tendency to restrict $\mathrm{CO}_{2}$ emissions, which is one of the main causes of the greenhouse effect. Especially indispensable in this respect is a reduction of $\mathrm{CO}_{2}$ emissions from coalfired power plants. The increasing attractiveness of the sorption methods of $\mathrm{CO}_{2}$ capturing from coal power plant flue gas (compared to the preferred currently absorption methods), which can be observed in recent years, is linked 
directly with the advent and development of new, efficient $\mathrm{CO}_{2}$ sorbents. These sorbents include amine-modified mesoporous silica, in which the porous substrate is modified with amine. The attractiveness of polymer-modified mesoporous materials as adsorbents may continue to increase because there is a possibility of synthesizing mesoporous materials, such as MCM-41, using FA as the source of Si. Adsorbents produced from FA could become more attractive $\mathrm{CO}_{2}$ adsorbents than those synthesized classically, owing to, for instance, their production cost. The utilization of FA as the source of $\mathrm{Si}$ in the synthesis of mesoporous molecular sieves creates a situation, where a waste product of coal combustion becomes in part an efficient $\mathrm{CO}_{2}$ adsorbent.

On the basis of studies available in the literature [3-8], the $\mathrm{Si} / \mathrm{Al}$ ratio and $\mathrm{Si}$ contents in the FA filtrate can be ranked amongst the main factors influencing the synthesis of mesoporous materials from FA. It is known, that this ratio depends not only on the method of recovery of Si and $\mathrm{Al}$ from the solution, but in particular also on the chemical and mineralogical composition of FA, from which it is obtained. Although some information on the synthesis of the MCM-41 mesoporous material from FA can be found in the literature, no determination of the suitability of different types of FA for silica extraction and mesoporous materials synthesis has been made anywhere. It is important therefore to determine $\mathrm{Si} / \mathrm{Al}$ ratio in filtrates from different FA types and to assess its influence on the formation of mesoporous materials and their quality.

As indicated by the conducted research [12-17], thermogravimetric analysis (TGA) provides a lot of valuable information both on the thermal behaviour of samples of mesoporous materials and on the course of their synthesis process itself. Thermal analysis is used [12-17] for the TG monitoring of the synthesis of MCM-41 mesoporous materials being obtained from silicon sources, such as regular silica-gel or colloidal fumed silica, which allows the evaluation of the effect of adjusting $\mathrm{pH}$ during the hydrothermal synthesis on the quality of the obtained material. The monitoring encompasses also the process of removing the surfactant from the MCM-41 materials, serving for the determination of the appropriate time and temperature of calcination to obtain a good-quality mesoporous material. Thanks to the TG method, it is also possible to determine the kinetics of surfactant decomposition $[15,16]$.

Because the studies carried out so far lack the analyses of this type for MCM-41 materials produced from a different silicon source, which is the extract from the waste products of coal combustion, i.e. FA, this article has presented the use of TGA for determining the thermal behaviour of FA-based MCM-41 mesoporous materials. This study has established the range of temperatures corresponding to the desorption of water, decomposition of the surfactant and condensation of silanol, thereby making the overall quality assessment of FA-based MCM-41 mesoporous materials, obtained on the basis of different types of $\mathrm{FA}$ (with different $\mathrm{Si} / \mathrm{Al}$ ratio) originating from ten Polish electric power stations.

\section{Experimental}

\section{Starting material}

As the starting material for the synthesis of the MCM-41 mesoporous materials cetyltrimethylammonium bromide (CTAB: $\mathrm{C}_{16} \mathrm{H}_{33}\left(\mathrm{CH}_{3}\right)_{3} \mathrm{NBr}$ ), sodium hydroxide, sulphuric acid (VI) and deionized water were used as raw materials. All chemicals were purchased from Aldrich. As the silicon sources for the synthesis of the MCM-41 mesoporous materials, three types of FA were used, which originated from the combustion of hard (samples nos. 2 and 3) and brown (sample no. 1) coal in pulverized-fuel (PC) boilers.

\section{Synthesis}

In order to extract silicon (in the form of sodium silicate) from FA, a method consisting in the fusion of FA with sodium hydroxide was used [1], followed by dissolving the formed solid substance in water. According to this methodology, FA $(25 \mathrm{~g})$ and sodium hydroxide $(30 \mathrm{~g})$ were used for the sintering of FA with sodium hydroxide so as to obtain an $\mathrm{NaOH}$ :ash weigh ratio of 1.2. After being accurately weighted, sodium hydroxide was ground in an agate mortar to obtain powder. Then, the weighted amount of ash was added and ground with $\mathrm{NaOH}$ until a homogeneous mixture was obtained. The powder so obtained was put in a porcelain evaporating dish and transferred to an oven, where it was heated according to the following programme: increasing temperature from 25 to $500{ }^{\circ} \mathrm{C}-1{ }^{\circ} \mathrm{C} / \mathrm{min}$; holding at $500{ }^{\circ} \mathrm{C}$ for $1 \mathrm{~h}$. After completion of the ovenheating programme, the product was left in a desiccator to cool down. Then, the mixture was carefully comminuted by grinding and, after weighing, it was transferred to a large beaker, to which an appropriate amount of water was poured so as to obtain a water to product/weight ratio of 4:1. The whole mixture was stirred at room temperature for $24 \mathrm{~h}$, and then vacuum filtered. The solution thus obtained containing sodium silicate was subjected to ICP analysis (using a Varian ICP-OES VISTA-MPX emission spectrometer) for the following elements: $\mathrm{Si}, \mathrm{Al}, \mathrm{Na}, \mathrm{Ca}, \mathrm{Fe}$ and $\mathrm{Mg}$. The obtained sodium silicate solution, after having been weighed, was transferred to a large polyethylene beaker and was stirred using a mechanized stirrer. After a while, a surfactant (CTAB) was started to be slowly added 
by drops in such an amount that the Si:CTAB weigh ratio was 20.5. After the surfactant had been added, the $\mathrm{pH}$ of the solution was adjusted so as to make its value to be 11 . Sulphuric acid (VI) was used for this purpose. After obtaining the prescribed $\mathrm{pH}$ value, the whole mixture was stirred for another $30 \mathrm{~min}$, and then the $\mathrm{pH}$ value was checked again and adjusted accurately to 11 . Afterwards, the mixture was poured to a polyethylene bottle and put in an oven for $24 \mathrm{~h}$ at a temperature of $100{ }^{\circ} \mathrm{C}$. Then, the $\mathrm{pH}$ value was corrected again to 11 , and the mixture was placed in the oven for another $24 \mathrm{~h}$ at $100{ }^{\circ} \mathrm{C}$. Subsequently, the obtained solid substance was separated from the solution using a foam funnel under vacuum and flushed with approx. $200 \mathrm{~mL}$ of distilled water. The obtained material was first dried at $60{ }^{\circ} \mathrm{C}$ for $24 \mathrm{~h}$, and then calcined at $500{ }^{\circ} \mathrm{C}$ (with temperature increase at the rate of $5{ }^{\circ} \mathrm{C} /$ $\mathrm{min}$ ), with dried helium being passed through the oven at a rate of $60 \mathrm{~mL} / \mathrm{min}$ during the whole period of temperature increase and during the first hour of calcinations. The synthesized samples were named F-MCM-41(x) where $x$ denotes the number of FA from which the Si extract was obtained.

\section{Characterization}

The obtained materials were characterized by TG (Metler Toledo TGA/SDTA 851e). Subjected to analysis were three F-MCM-41 as-synthesized mesoporous materials.

The mesoporous samples were heated from room temperature to $1,000{ }^{\circ} \mathrm{C}$ at the rate of $20^{\circ} \mathrm{C} / \mathrm{min}$ in a flow $\left(50 \mathrm{~cm}^{3} \mathrm{~min}^{-1}\right)$ of nitrogen. The formation of a mesoporous structure for all samples was also confirmed by powder $\mathrm{X}$-ray diffraction (XRD). XRD patterns were recorded on a Bruker AXS D8 Advance diffractometer using $\mathrm{Cu} \mathrm{K \alpha}$ radiation of wavelength $0.15405 \mathrm{~nm}$. Diffraction data were recorded between $1.4^{\circ}$ and $8^{\circ} 2 \Theta$ at an interval of $0.02^{\circ}$ $2 \Theta$. The porous properties of FA-based MCM-41 mesoporous materials were investigated by determining their $\mathrm{N}_{2}$ gas adsorption and desorption isotherms at $77 \mathrm{~K}$, using an ASAP 2010 Instrument (Micromeritics). The specific surface area for all samples was calculated by the BET method from the linear part of BET plot according to IUPAC recommendations using the adsorption isotherm (relative pressure $\left.\left(p / p_{0}\right)=0.05-0.23\right)$. Samples were outgassed under $1 \mathrm{mPa}$ for $24 \mathrm{~h}$ at $573 \mathrm{~K}$ before nitrogen adsorption measured. The microstructures and chemical composition of the all mesoporous silica materials were observed using a Electron Microscopes (Tesla BS-301-Satellite) coupled with energy dispersive X-ray spectroscopy (EDXS). For one of the obtained samples [F-MCM-41(3)] solid-state ${ }^{27} \mathrm{Al}$ MAS NMR and ${ }^{29} \mathrm{Si}$ MAS NMR spectra were recorded on a Bruker MSL $400 \mathrm{P}$ Spectrometer.

\section{Results and discussion}

Fly ashes

The chemical composition of starting FA is given in Table 1. As seen from the table, the contents of the main FA constituents, i.e. $\mathrm{SiO}_{2}$ and $\mathrm{Al}_{2} \mathrm{O}_{3}$, vary, depending on the FA type. The content of silicon in individual samples ranging from $46.15 \%$ (sample no. 3 ) to $54.77 \%$ (sample no. 1). For $\mathrm{Al}$, the lowest content was found in sample no. 1 (22.56\%), and the highest in sample no. $3(26.25 \%)$. The highest $\mathrm{Si} / \mathrm{Al}$ ratio was found for $\mathrm{FA}$ no. $1(\mathrm{Si} / \mathrm{Al}=2.43)$, and the lowest for the FA no. $3(\mathrm{Si} / \mathrm{Al}=1.76)$. From the point of view of using FA for the synthesis of mesoporous materials, their mineralogical composition and content of reactive $\mathrm{SiO}_{2}$ are of paramount importance. The mineral composition of FA was determined by XRD. The determinations of the relative amounts of crystalline components in the FA sample were made by the internal standard method. The standard diffraction patterns were obtained using the same measurement conditions as in the case of assaying the samples. The following standard substances were used: $\mathrm{SiO}_{2}$ (quartz, washed, calcined and analytically pure from Supelco), mullite (from Alfa Aesar), calcite (natural mineral from Alfa Aesar); calcium oxide (99.95\% Ca from Strem Chemicals); (III) iron oxide, red (hematite 98.8-Fe from Strem Chemicals); (II, III) iron oxide, black (magnetite 95\% from Strem Chemicals); calcium sulphate (anhydrite and analytically pure from POCh Gliwice).

Content of reactive $\mathrm{SiO}_{2}$ in the $\mathrm{FA}$ was determined according to the PN-EN-197-1:2001 standard. The examination of FA using X-ray diffractometry (Fig. 1) identified particular mineralogical phases. The $\mathrm{X}$-ray analysis pulverized-fuel boiler FA showed that the main phases present in this type of FA were crystalline components, such as: quartz (JCPDS:00-005-0490), mullite (JCPDS:01-0841205), hematite (JCPDS:01-089-2810), magnetite (JCPDS: 00-003-0862), and hercynite (JCPDS:01-085-1828), along with amorphous aluminosilicate glasses, the presence of which is indicated by a wide peak at about $25^{\circ}, 2 \Theta$. The contents of particular crystalline phases present in FA (based on the XRD analysis) are given in Table 2. The non-crystalline phase in the case of pulverized-fuel boiler FA are aluminosilicate glasses. Of the pulverized-fuel boiler FA, the most crystalline quartz was found in FA no. 2 (18 wt\%). In FA no. 2, the highest amount of the other crystalline component, i.e. mullite, was also found (30 wt $\%)$, contents of which were high in FA nos. 1 and 3, too. The highest hematite and magnetite contents were found in FA no. 3. All of the FA examined showed also a high content of reactive $\mathrm{SiO}_{2}: 37.21$, 39.7 and 37.17 for FA 1, 2 and 3, respectively. A decisive stage in the synthesis of mesoporous materials from FA is the extraction of $\mathrm{Si}$ and $\mathrm{Al}$ from the FA. The most effective 
Table 1 Chemical composition of FA (wt \%)

\begin{tabular}{|c|c|c|c|c|c|c|c|c|c|c|c|c|}
\hline \multirow[t]{2}{*}{ Fly ash } & \multicolumn{12}{|c|}{ Element as oxide } \\
\hline & LOI & $\mathrm{SiO}_{2}$ & $\mathrm{Al}_{2} \mathrm{O}_{3}$ & $\mathrm{Fe}_{2} \mathrm{O}_{3}$ & $\mathrm{CaO}$ & $\mathrm{MgO}$ & $\mathrm{Na}_{2} \mathrm{O}$ & $\mathrm{K}_{2} \mathrm{O}$ & $\mathrm{Mn}_{2} \mathrm{O}_{3}$ & $\mathrm{P}_{2} \mathrm{O}_{5}$ & $\mathrm{TiO}_{2}$ & $\mathrm{SiO}_{2} / \mathrm{Al}_{2} \mathrm{O}_{3}$ \\
\hline 1 & 1.26 & 54.77 & 22.56 & 4.46 & 7.9 & 0.66 & 1.78 & 1.09 & 0.16 & 0.004 & 2 & 2.43 \\
\hline 2 & 1.2 & 50.21 & 26.31 & 4.5 & 3.11 & 2.12 & 0.3 & 2.88 & 0.16 & 0.74 & 1.14 & 1.9 \\
\hline 3 & 3.56 & 46.15 & 26.25 & 8.4 & 4.87 & 0.58 & 3.11 & 1.8 & 0.2 & 0.005 & 0.6 & 1.76 \\
\hline
\end{tabular}

LOI loss on ignition

method of executing it is by fusion of the FA with solid $\mathrm{NaOH}$. As a result of this process, more of the insoluble calcium silicates and aluminosilicates present in the FA pass into soluble sodium silicates and aluminosilicates. As a result of this, $\mathrm{Si}$ and $\mathrm{Al}$ extracts can be obtained from the FA, which will have much higher concentrations of these elements compared to the other method, that is the hydrothermal reaction of FA with the solution of $\mathrm{NaOH}$. The extraction of Si from FA carried out in this study by the method of fusion with $\mathrm{NaOH}$ yielded a filtrates, chemical composition of which is shown in Table 3. As noticed form the table, in all of the filtrates, the concentration of $\mathrm{Si}$ is significantly higher than that of Al. In view of the presence of aluminium in the filtrates, the final material after synthesis should be aluminosilicate. The highest $\mathrm{Si}$ content was found in the filtrates obtained from FA no. $2\left(6,880 \mathrm{mg} / \mathrm{dm}^{3}\right)$. This fact can be explained by the high degree of solution of the $\mathrm{Si}$ and $\mathrm{Al}$ from quartz and mullite during the fusion of FA with $\mathrm{NaOH}$. The highest $\mathrm{Si} / \mathrm{Al}$ ratio is found for extract no. 1 (9.31). The extracts from all of the FA had already a markedly higher $\mathrm{Si}$ / $\mathrm{Al}$ ratio (respectively: 9.13, 6.8 öand 5.30) and, at the same time, a correspondingly high Si content (above 4,560), and thus proved to be useful for the synthesis of MCM-41 aluminosilicate materials (Fig. 2). The high content of reactive $\mathrm{SiO}_{2}$ in all of the samples explains the high $\mathrm{Si}$ content found in the filtrates obtained from these ashes.

Owing to the different mineralogical composition of FA and thereby the different degree of solubility of Si and Al, the contents of these elements in filtrates differ from their contents in the FA from which they get extracted. For all of the FA, the $\mathrm{Si} / \mathrm{Al}$ ratio in the obtained filtrate was higher than that in the initial FA. It is known that Si dissolves the most readily from aluminosilicate glasses, harder from quartz, and most hardly from mullite, but the employed $\mathrm{NaOH}$ fusion method enables a very effective extraction of $\mathrm{Si}$ from quartz and mullite. Apart from the main constituents, such as $\mathrm{Si}, \mathrm{Al}$ and $\mathrm{Na}$, the other impurities found in the extracted solutions were $\mathrm{Ca}, \mathrm{Fe}$ and $\mathrm{Mg}$ (Table 3).

\section{FA-based MCM-41}

For the assessment of MCM-41 formation from FA extracted solutions, XRD analysis was employed for
F-MCM-41 mesoporous materials. The performed XRD analysis of samples obtained in this study showed that the F-MCM-41 mesoporous materials were obtained from all FA. This is confirmed by the diffraction patterns shown in Fig. 2, on which well-developed XRD reflections can be observed in the low-angle range - (a very strong peak at approx. $2.3^{\circ} 2 \Theta$, resulting from the (100) index) for the samples obtained from FA. The diffraction peak related to the (100) plane is seen to be more intense for the samples obtained from FA 2 and 1 when compared to sample obtained from FA 3, which can be interpreted as an indication of higher ordering of the mesopore channels. As shown in Fig. 2 (for sample no. 1), two weak peaks ((110) and (200)) were also distinguished as peaks characteristic of the MCM-41 family, suggesting a successful formation of 2-dimensional hexagonal structure [9].

The formation of the mesoporous structure was also confirmed by sorption tests of the synthesized samples, which allowed for the determination of the specific surface area and pore size of materials obtained. The achieved values of structure/texture parameters for the obtained material samples are presented in Table 4. The BET specific surface area of the mesoporous materials F-MCM-41 obtained on the basis of FA was from 350.6 [F-MCM41(3)] to $610 \mathrm{~m}^{2} \mathrm{~g}^{-1}$ [F-MCM-41(2)]. In turn, the pore volume and diameter, as calculated for the sample of the greatest area, the F-MCM-41(2) mesoporous materials obtained from FA, amounted to, respectively: $1.03 \mathrm{~cm}^{3} \mathrm{~g}^{-1}$ and $6.2 \mathrm{~nm}$. The values of structure parameters (surface areas and pore diameters) confirm the mesoporous nature of the synthesized materials, despite lower than usual values observed for commercial Al-MCM-41 material synthesized from chemically pure $\mathrm{Si}$ sources. The cause of the specific surface area and pore volume of commercial Al-MCM-41 being higher compared with the F-MCM-41 made from FA was, according to Misran $[6,7]$ the fact that mesoporous materials prepared from a pure silica source would be more reactive and a larger amount of silicate anions would be present in the mixture. The larger amount of silicate anions present could condensate and hydrolyse resulting in a higher surface area. On the other hand, Chandrasekar et al. [8] explains the low specific area of FA-derived mesoporous materials being due to the 

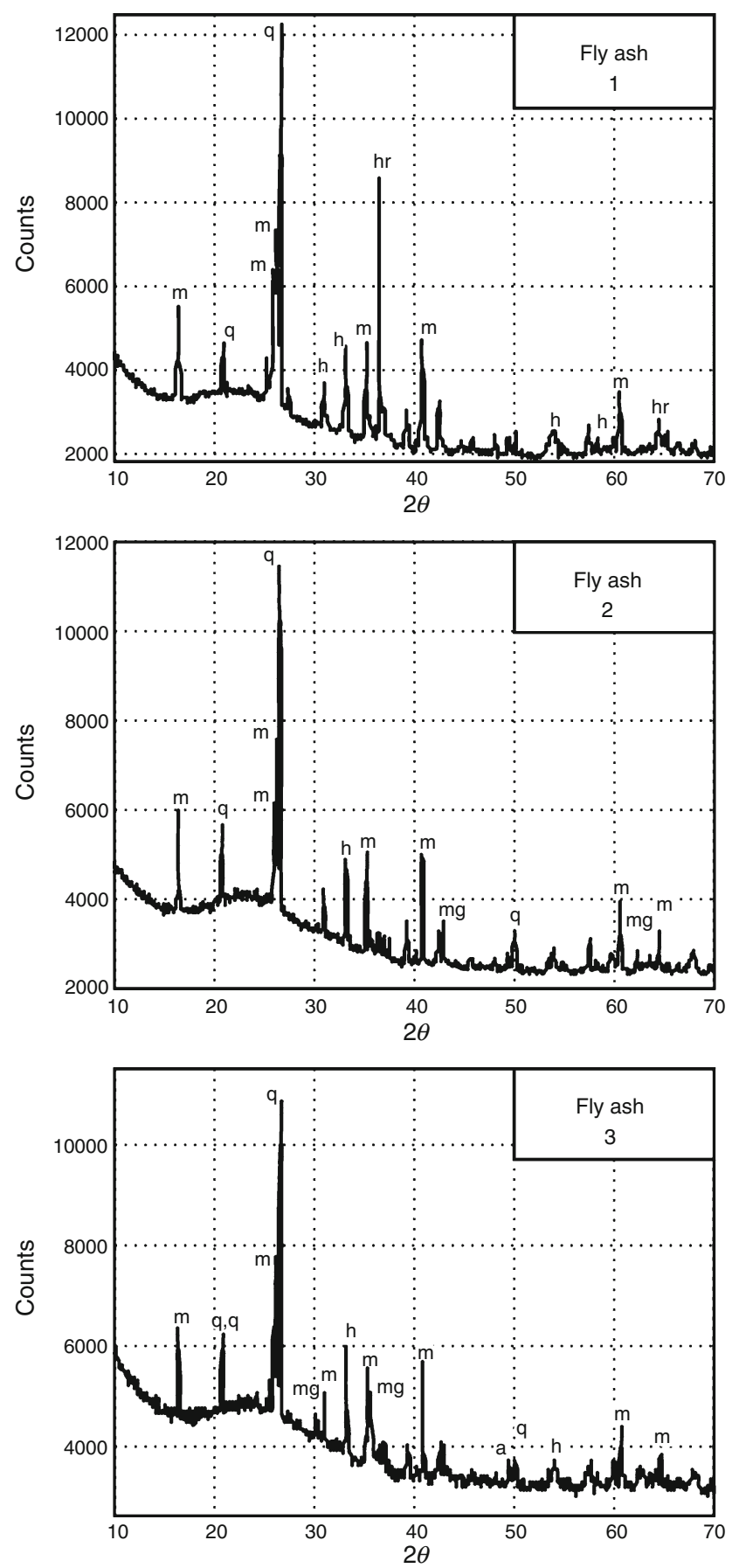

Fig. 1 XRD patterns of FA ( $m$ mullite, $q$ quartz, $a$ anhydrite, $m g$ magnetite, $h$ hematite, $h r$ hercynite) inclusion of $\mathrm{Al}$ into the silica structure under alkaline conditions. It is known that the specific area decreases also with the increase in the amount of impurities present in the sample (included in the silica framework) [8]. From amongst the samples tested, the smallest specific area was exhibited by the F-MCM-41(3) sample which contained the most $\mathrm{Al}$ (the lowest $\mathrm{Si} / \mathrm{Al}$ ratio) and, at the same time, most impurities left from the FA extract (Table 5).

Figure 3 shows the $\mathrm{N}_{2}$ adsorption/desorption isotherms of F-MCM-41 mesoporous materials synthesized from FA. The $\mathrm{N}_{2}$ adsorption/desorption isotherms of F-MCM-41 synthesized from FA are isotherms of type IV according to the IUPAC classification with a sharp capillary condensation step at relative pressure of $0.25-0.45$ [18]. This isotherm has four well-defined ranges. At low relative pressures, a gradual increase is observed, which is caused by the mono- and multilayer adsorption on the pore walls; then a sharp increase is observed at the average $p / p_{0}$ values, which results from capillary condensation; then a gradual linear increase at high $p / p_{0}$ values is seen, which is associated with the adsorption on the external surface of the samples, and finally a sharp rise in nitrogen uptake filling all other available pores as the pressure reached saturation $\left(p / p_{0}=1\right)$ [18]. All $\mathrm{N}_{2}$ adsorption-desorption isotherms exhibit hysteresis loop also at very high relative pressure $\left(p / p_{0}=0.9-1\right)$. This is likely to be caused by capillary condensation in large meso- or macropores existing in the inter-particle space. In the F-MCM-41(3) and the F-MCM41(1) samples, it can also be found that the hysteresis loop is very wide $\left(p / p_{0}=0.5-1.0\right)$, which means that these materials contain channels in a wide range of diameters. According to the literature data, the hysteresis loop might indicate the monodispersion of the material, and its absence can be attributed to the heterogeneity of pore size in an MCM-41 type material [19]. Figure 4 shows pore size distributions for the calcined FA-derived F-MCM-41 materials. The pore size distribution for these samples, as calculated by the BJH method, shows a sharp peak at about $2.7 \mathrm{~nm}$ for the F-MCM-41(2) sample and wider peaks for the F-MCM-41(1) and the F-MCM-41(3) samples at about $2.2 \mathrm{~nm}$. In Fig. 4, an arm is also visible after the sharp peaks for all the samples, which probably indicates interparticle pores. Similar results were obtained by Yang [20] and Adjdir [21] in their studies.

Table 2 Semi-quantitative composition of FA (wt $\%$ )

\begin{tabular}{lclllllll}
\hline Fly ash & Quartz & Mullite & Hematite & Magnetite & Anhydrite & Calcite & CaO & Non-crystalline phase \\
\hline 1 & 5.4 & 15 & 4.1 & - & - & - & - & 75.5 \\
2 & 18 & 30 & 3.0 & 1.0 & - & - & $<1$ & 47.0 \\
3 & 8 & 20 & 15.0 & 7.5 & $<1$ & - & - & 48.5 \\
\hline
\end{tabular}


Table 3 Concentrations of $\mathrm{Si}, \mathrm{Al}$ and other impurities in the supernatants of FA (method of FA fusion with $\mathrm{NaOH}$ )

\begin{tabular}{lccc}
\hline Concentrations $/ \mathrm{mg} / \mathrm{dm}^{3}$ & \multicolumn{2}{c}{2} & 3 \\
\hline $\mathrm{Si}$ & 4930 & 6880 & 4560 \\
$\mathrm{Al}$ & 540 & 1012 & 860 \\
$\mathrm{Ca}$ & 5.3 & 3.7 & 6.9 \\
$\mathrm{Mg}$ & 0.1 & 0.1 & 0.2 \\
$\mathrm{Fe}$ & 1.8 & 2.5 & 5.8 \\
$\mathrm{Na}$ & 76000 & 70000 & 70000 \\
$\mathrm{Si} / \mathrm{Al}$ & 9.13 & 6.8 & 5.30 \\
\hline
\end{tabular}

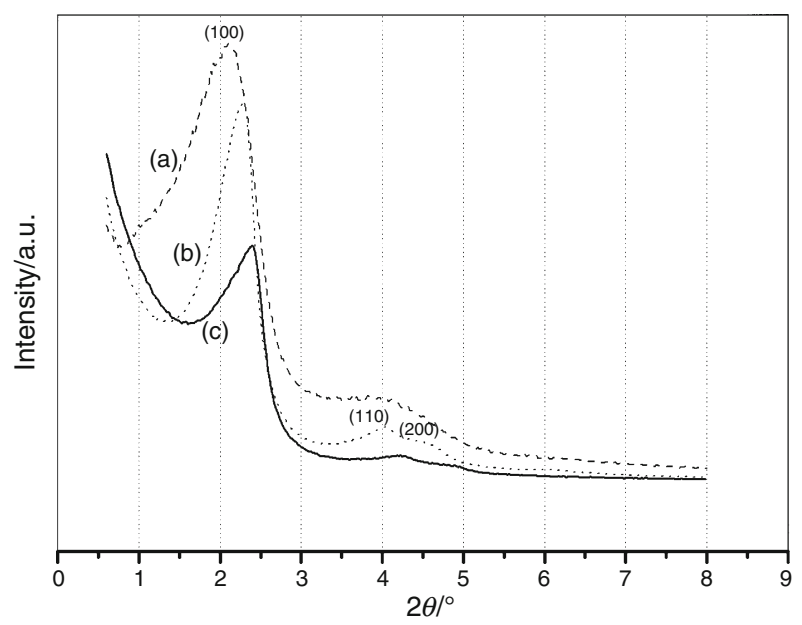

Fig. 2 XRD patterns of as-synthesized F-MCM-41 mesoporous materials: (a) F-MCM-41(2), (b) F-MCM-41(1), (c) F-MCM-41(3)

Table 4 Textural parameters of FA-based calcined F-MCM-41

\begin{tabular}{llll}
\hline Sample & $\begin{array}{l}\text { Specific } \\
\text { surface area, } \\
S_{\mathrm{BET}} / \mathrm{m}^{2} \mathrm{~g}^{-1}\end{array}$ & $\begin{array}{l}\text { Specific } \\
\text { pore volume/ } \\
\mathrm{cm}^{3} \mathrm{~g}^{-1}\end{array}$ & $\begin{array}{l}\text { Pore } \\
\text { diameter/ } \\
\mathrm{nm}\end{array}$ \\
\hline F-MCM-41(1) & 418 & 0.39 & 3.9 \\
F-MCM-41(2) & 610 & 1.03 & 6.2 \\
F-MCM-41(3) & 350.6 & 0.28 & 4.6 \\
$\begin{array}{l}\text { Commercial Al- } \\
\text { MCM-41 }\end{array}$ & 918.9 & 1.12 & 3.5 \\
\hline
\end{tabular}

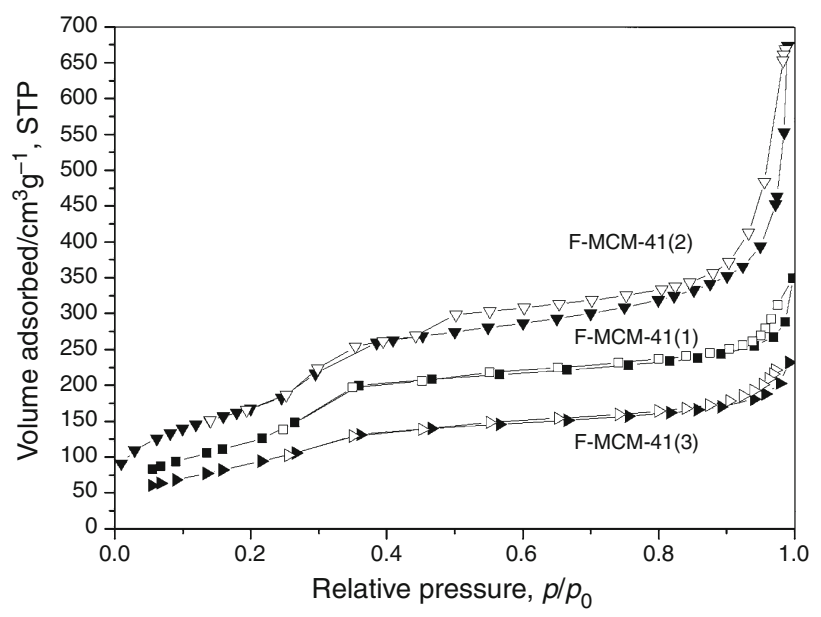

Fig. $3 \mathrm{~N}_{2}$ adsorption/desorption isotherms for the calcined F-MCM41 mesoporous materials

Figure 5 shows SEM photographs of FA-derived F-MCM-41 materials (calcined). The F-MCM-41 samples exhibit agglomerates (of hexagonally shaped particles) with sizes between 3 and $200 \mu \mathrm{m}$. It was observed that the sizes of particles are different, depending on the sample type (sample quality). For the F-MCM-41(1) and the F-MCM-41(2) samples (of good quality, according to $\mathrm{XRD}$ ), the greatest regular morphology and a very low content of impurities (as confirmed by EDXS) were found.

Chemical composition of the mesoporous materials obtained based on FA extracts was analysed by EDXS and the major elements present in the samples are indicated in Table 5. As shown in Table 5, the $\mathrm{Si} / \mathrm{Al}$ ratio for selected samples of mesoporous materials produced from FA ranged from 11.22 (3) to 13.47 (2), being definitely higher than the $\mathrm{Si} / \mathrm{Al}$ in the initial FA (from 1.75 to 2.42) and in the filtrates obtained on their basis (from 5.3 to 9.1). Apparently, the solution of silicates is more effective than that of aluminium compounds during synthesis. Aside from the main components, i.e. $\mathrm{Si}$ and $\mathrm{Al}, \mathrm{Fe}, \mathrm{Ca}, \mathrm{K}$ and $\mathrm{Na}$, were also found in the obtained materials. These impurities were present both within the sample, as well as on its external surface in the pores of the ash-derived MCM-41 mesoporous material. According to Chang, who obtained similar results, these impurities do not hamper the synthesis of the MCM-41 material. The highest content of aluminium

Table 5 Chemical compositions of mesoporous materials F-MCM-41 (wt \%)

\begin{tabular}{llllllll}
\hline Mesoporous materials & \multicolumn{2}{l}{ Elemental composition (wt\%) } & & \\
\cline { 2 - 7 } & $\mathrm{Si}$ & $\mathrm{Al}$ & $\mathrm{Na}$ & $\mathrm{K}$ & $\mathrm{Fe}$ & $\mathrm{Ca}$ & $\mathrm{Si} / \mathrm{Al}$ \\
\hline F-MCM-41(1) & 87.80 & 6.91 & 4.19 & 0.78 & 0.25 & 0.07 \\
F-MCM-41(2) & 88.79 & 6.59 & 3.78 & 0.59 & 0.15 & 0.10 & 12.7 \\
F-MCM-41(3) & 85.00 & 7.57 & 5.89 & 0.9 & 0.5 & 0.14 \\
\hline
\end{tabular}




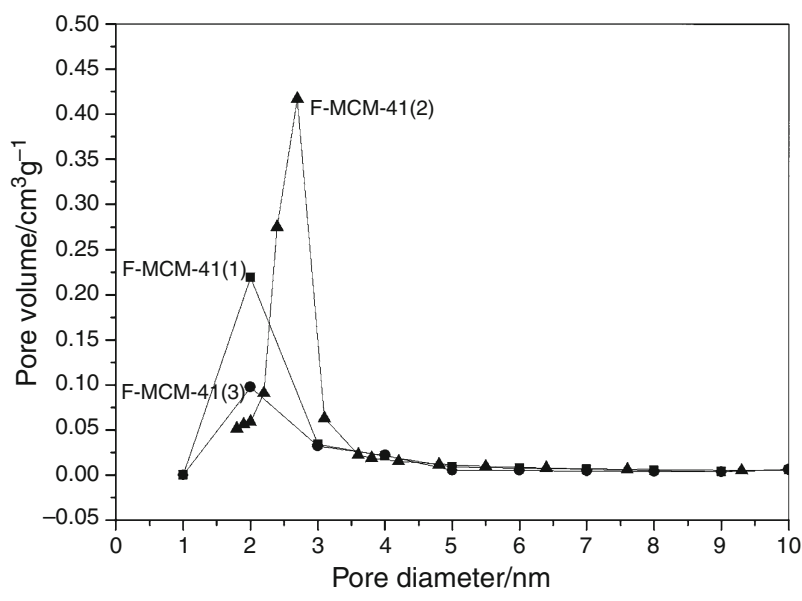

Fig. 4 Pore size distribution curve of the calcined F-MCM-41 materials from FA (calculated from the adsorption using the Barrett-Joyner-Halenda formula)

(7.57 wt \%) and the highest contents of impurities were found in the F-MCM-41(3) ash sample. This is one of the causes of the smaller specific area for this sample compared with the other two F-MCM-41 samples, because, according to the literature data, irrespective of the Al source used during the synthesis of aluminosilicate MCM41 from chemically pure components, the specific area and the pore diameter always decrease with increasing amount of introduced aluminium [22]. This sample exhibited also the lowest degree of ordering of all the FA-based F-MCM41 samples. Figure 6a shows ${ }^{27} \mathrm{Al}$ MAS NMR spectra for the calcined FA extract mesoporous materials F-MCM41(3). The ${ }^{27} \mathrm{Al}$ MAS NMR spectra indicate the chemical state of $\mathrm{Al}$ in the structure of the material obtained. The chemical shift in the spectrum shows a single very strong peak at $52 \mathrm{ppm}$ assigned to tetrahedral $\left(\mathrm{T}_{\mathrm{d}}\right)$ coordination. According to Kumar et al. [4], this provides direct evidence for the fact that $\mathrm{Al}$ is included in the structure, and the FA filtrate prefers the coordination $\mathrm{T}_{\mathrm{d}}$. This is a direct proof of $\mathrm{Al}$ inclusion in the framework of MCM-41. It is interesting to note that no octahedral $\left(\mathrm{O}_{\mathrm{h}}\right)$ coordination, with a corresponding peak at $0 \mathrm{ppm}$, was found in the F-MCM-41(3) sample, despite the high $\mathrm{Al}$ content of the sample $(\mathrm{Al}=7.57 \mathrm{wt} \%)$. The more the aluminium is included in the sample (Table 5), the more the $\mathrm{Na}^{+}$ions are present in it, as they compensate for the charge of the silica framework. The smaller amount of aluminium included in the sample indicates that for some reasons, e.g., a lower $\mathrm{pH}$, the $\mathrm{Al}$ template interaction was smaller.

Figure $6 \mathrm{~b}$ shows ${ }^{29} \mathrm{Si}$ MAS NMR spectra for the calcined FA extract mesoporous materials F-MCM-41(3). The spectrum of the calcined Al-MCM-41 shows the presence of two main resonance peaks: $-102 \mathrm{ppm}$ for $Q_{3}$, i.e. $\mathrm{Si}(\mathrm{OSi})_{3} \mathrm{OH}$, and $-109 \mathrm{ppm}$ for $Q_{4}$, i.e. $\mathrm{Si}(\mathrm{OSi})_{4}$, which are much wider than those observed for pure $\mathrm{SiO}_{2}$ materials. A peak at $-93 \mathrm{ppm}$ for $Q_{2}$ can also be observed (but a very weak one). In Kumar's view, the presence of $Q_{4}$ and $Q_{3}$ species is evidence for a higher degree of condensation of the silanols groups when the synthesis is carried out with $\mathrm{pH}$ adjustment. Kumar [4] has also found that the presence a considerable number of $\mathrm{Al}$ nuclei in the sample results in a quadripolar broadening of the $\mathrm{Si}$ signals observed $\mathrm{w}$ spectrum of ash Al-MCM-41.

Thermal analysis

For the as-synthesized materials derived from FA, TGA was performed using a Mettler Toledo TGA/SDTA 851e thermobalance. Figures 7 and 8 show TG and DTG curves of the F-MCM-41 mesoporous materials obtained from FA. Four or three mass losses can be observed on the TG and DTG curves for F-MCM-41 mesoporous materials. Table 6 reports the ranges of temperature for decomposition of the as-synthesized samples.

The first mass loss, amounting to approx. $5 \mathrm{wt} \%$ [for F-MCM-41(3) and F-MCM-41(2)] and 4 wt $\%$ [for F-MCM-41(1)] and occurring in the temperature range from 25 to $100{ }^{\circ} \mathrm{C}$, is caused by the thermodesorption of physically adsorbed water.

The second mass loss, amounting to approx. (21-30 wt\%) occurring in the temperature range from 100 to $355^{\circ} \mathrm{C}$ [for the samples of F-MCM-41(2) and F-MCM41(1)] and from 100 to $340{ }^{\circ} \mathrm{C}$ [for the sample F-MCM41(3)]. This mass loss is caused by the decomposition of the surfactant (breaking of the hydrocarbon chain). In the case of the decomposition of the surfactant for F-MCM41(2), a mass loss of $30 \mathrm{wt} \%$ was found. This mass loss was greater than the mass loss for the samples of F-MCM41(1) and F-MCM-41(3) - 28.5 and $21 \mathrm{wt} \%$, respectively. The maximum of this stage has moved from $225{ }^{\circ} \mathrm{C}$ [for
Fig. 5 SEM images of a FMCM-41(2), b F-MCM-41(1), and c F-MCM-41(3)
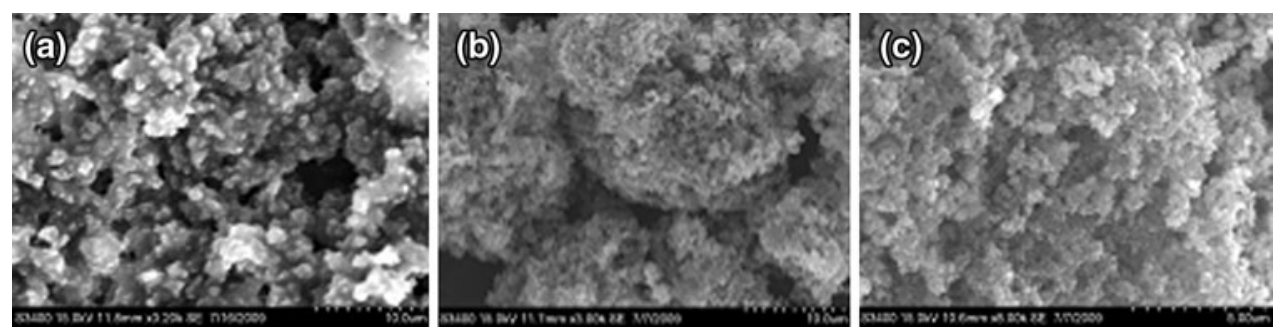
Fig. 6 a ${ }^{27} \mathrm{Al}$ MAS NMR

spectrum of the calcined F-MCM-41(3) prepared using FA as the starting material. b ${ }^{29} \mathrm{Si}$ MAS NMR spectrum of the calcined F-MCM-41(3) prepared using FA as the starting material (a)

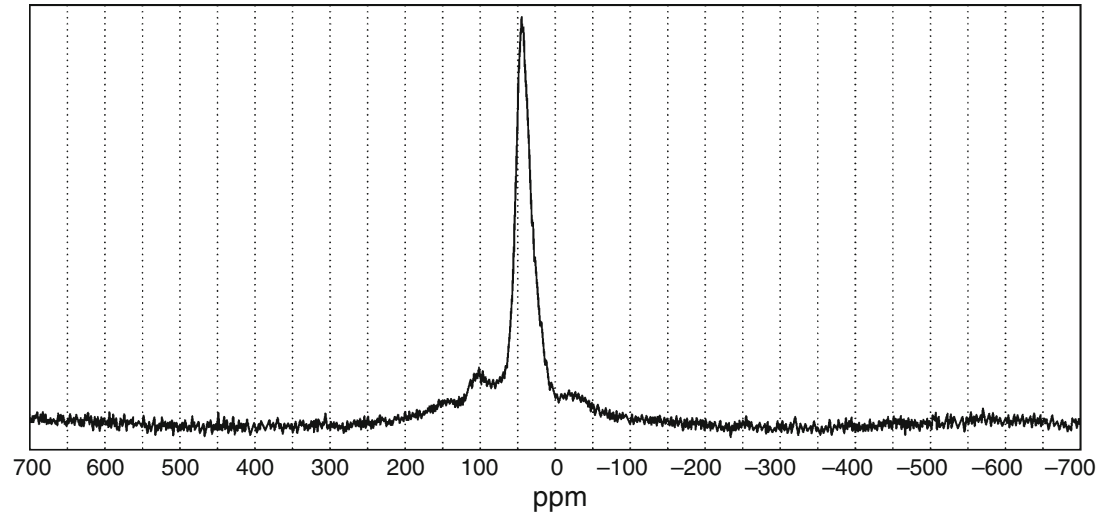

(b)
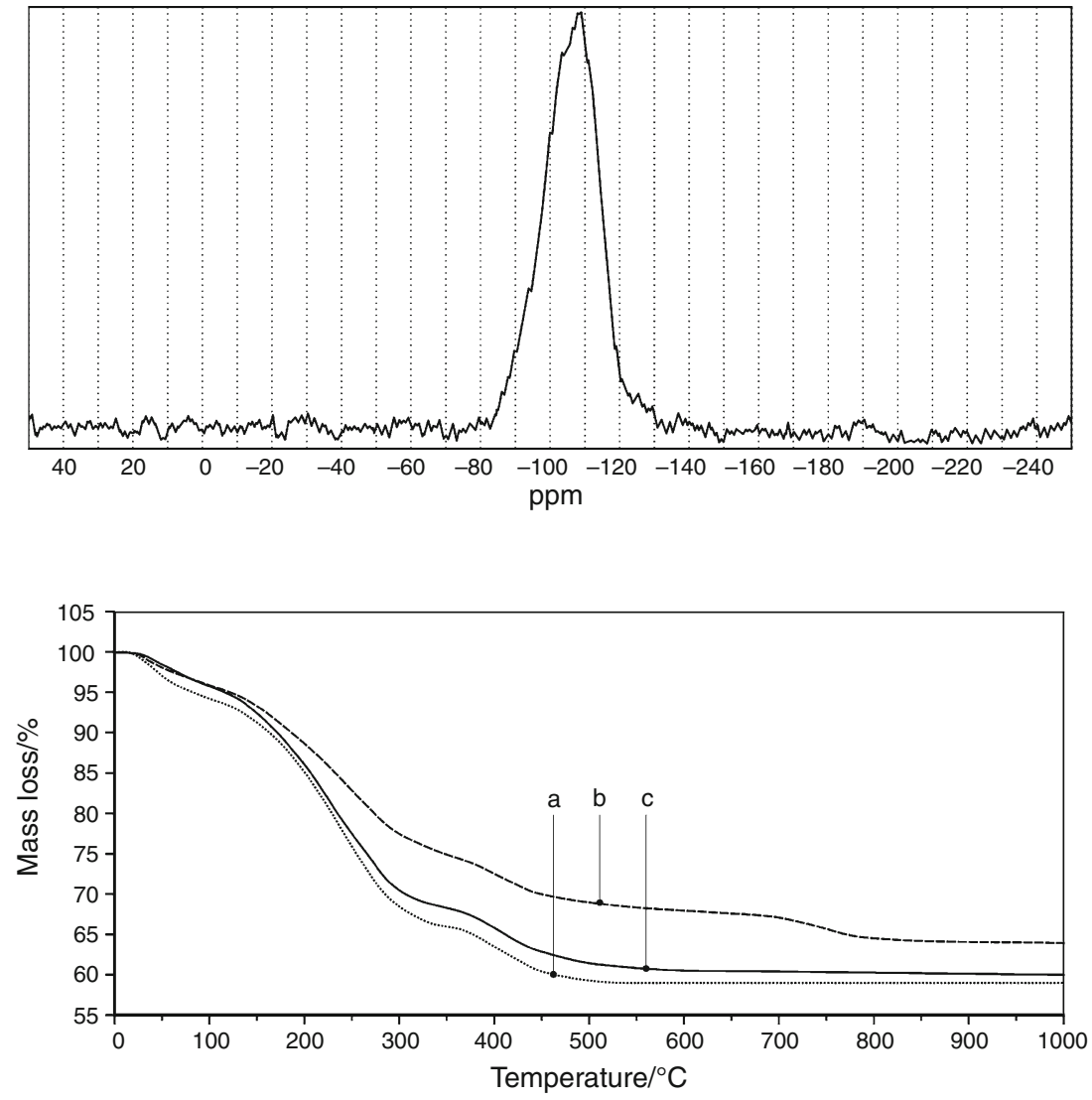

Fig. 7 TG curves for the assynthesized F-MCM-41 mesoporous materials: (a) FMCM-41(2), (b) F-MCM-41(3), (c) F-MCM-41(1)
F-MCM-41(2)] to $227{ }^{\circ} \mathrm{C}$ [for F-MCM-41(1)] and then to $265^{\circ} \mathrm{C}$ [for F-MCM-41(3)]. A shoulder on the DTG curve at $270{ }^{\circ} \mathrm{C}$ was observed for the samples of F-MCM-41(1) and F-MCM-41(2).

The least overall mass loss (36 wt $\%)$ and, at the same time, the least mass loss $(21 \mathrm{wt} \%)$ due to surfactant decomposition, as found for F-MCM-41(3), might indicate the fact that much less surfactant cations had combined with $\mathrm{Si}$ and $\mathrm{Al}$ species, compared with the remaining F-MCM-41 mesoporous materials. The maximum of surfactant removal for F-MCM-41(3) was also different from that for other samples (considerably higher). According to
Hui and Chao [5], TGA investigations of the Al-MCM-41 materials suggested a much stronger interaction of the organic template cations with $\mathrm{Al}$ species than with $\mathrm{SiO}^{-}$ (this explains the fact that the peaks of surfactant removal for the Al-MCM-41 samples are shifted towards higher temperatures compared to the silicon samples). Perhaps, the farther a peak is shifted, the more the Al species are incorporated into the sample (in this study, the largest shift of the peak was found for the MCM-41(3) sample). According to [13], if the surfactant removal peak occurs at higher temperatures, then this indicates that the surfactant is more difficult to decompose, and this in turn means that 
Fig. 8 DTG curves for the assynthesized F-MCM-41 mesoporous materials: (a) FMCM-41(2), (b) F-MCM-41(3), (c) F-MCM-41(1)

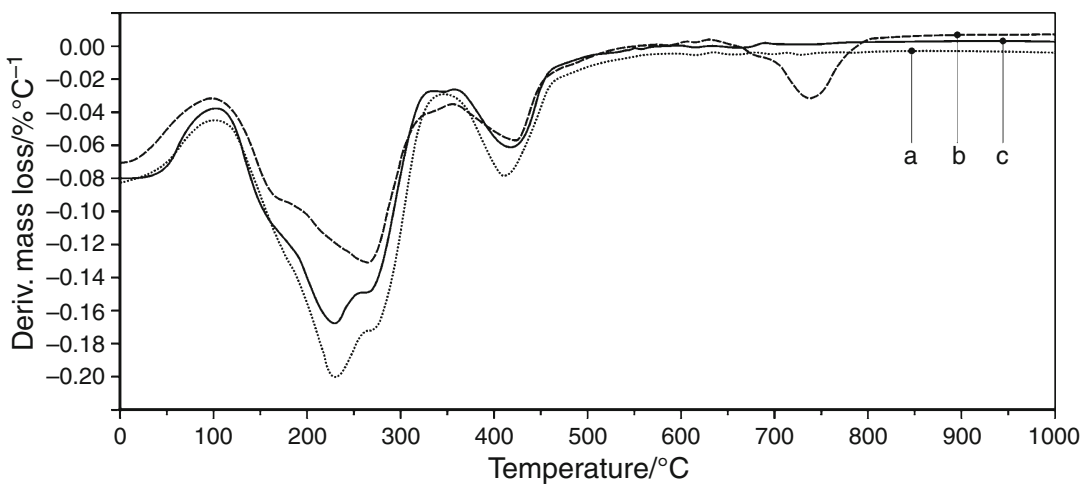

Table 6 Ranges of temperature for decomposition of the as-synthesized F-MCM-41 from FA

\begin{tabular}{lllc}
\hline Sample & F-MCM-41(1) & F-MCM-41(2) & F-MCM-41(3) \\
\hline $\begin{array}{l}\text { First mass } \\
\text { loss } /{ }^{\circ} \mathrm{C}\end{array}$ & $25-100$ & $25-100$ & $25-100$ \\
$\begin{array}{l}\text { Second mass } \\
\text { loss } /{ }^{\circ} \mathrm{C}\end{array}$ & $100-355$ & $100-355$ & $100-340$ \\
$\begin{array}{l}\text { Third mass } \\
\text { loss } /{ }^{\circ} \mathrm{C}\end{array}$ & $355-450$ & $340-500$ & $355-600$ \\
$\begin{array}{l}\text { Fourth mass } \\
\text { loss } /{ }^{\circ} \mathrm{C}\end{array}$ & - & - & $600-840$ \\
\hline
\end{tabular}

it interacts stronger with the silanol groups. Moreover, it is also known [12] that the template removal efficiency is higher for pure siliceous MCM-41 as compared with the aluminium containing MCM-41, and the F-MCM-41(3) sample had the highest $\mathrm{Al}$ content (Table 5) of all the samples examined. The investigation has shown, therefore, that the degree of surfactant removal depends on the properties of the F-MCM-41 material from which the surfactant is removed, and especially on its composition and structure.

For the F-MCM-41(3) sample, the lowest intensity of the XRD peak (Fig. 2), the smallest specific area (Table 3), the highest $\mathrm{Al}$ content (the lowest $\mathrm{Si} / \mathrm{Al}$ ratio) and the highest content of impurities left from the ash (Table 5) were found. This cam be explained by the lowest template removal efficiency which was achieved for this sample. For all the samples. the maximum of the surfactant removal appeared at temperatures higher than those observed for Al-MCM-41 classically synthesized (from pure Si and Al sources) which indicates that the surfactant cations interact more strongly with $\mathrm{Si}$ and $\mathrm{Al}$ cations.

It should be emphasized that the position of the desorption maxima of surfactant depends on the heating rate applied in the experiment. A high heating rate, as applied in the tests, may cause the maximum representing the process to be shifted to higher temperatures, as a significant shift of TGA curves to higher T normally takes place with increasing heating rate.

The quite different percentage values of surfactant loss, surfactant decomposition ranges and maxima, achieved for particular samples obtained from FA filtrates indicate different interactions between the associated surfactants due to the presence of $\mathrm{Si}$ and $\mathrm{Al}$ species (because the filtrates from FA differed in the contents of $\mathrm{Si}$ and $\mathrm{Al}$ and associated ions (impurities) (Table 5), which were absent in the case of Al-MCM-41 synthesis from the chemically pure sources of $\mathrm{Si}$ and $\mathrm{Al}$ ).

The third mass loss (Figs. 7, 8) is due to residual surfactant decomposition and water loss associated with condensation of silanol groups, with this mass loss occurring in the temperature range from 355 to $600{ }^{\circ} \mathrm{C}$ [F-MCM-41(3)], from 340 to $500{ }^{\circ} \mathrm{C}$ [F-MCM-41(2)] and from 355 to $450{ }^{\circ} \mathrm{C}$ [F-MCM-41(1)]. This loss amounted to 6, 6.5 and $7.5 \mathrm{wt} \%$ for the samples of F-MCM-41(2), F-MCM-41(1) and F-MCM-41(3), respectively. The maximum of this stage has moved from $410{ }^{\circ} \mathrm{C}$ [F-MCM$41(2)]$ to $418{ }^{\circ} \mathrm{C}$ [F-MCM-41(1)] and then to $423{ }^{\circ} \mathrm{C}$ [F-MCM-41(3)].

The fourth mass loss (from 600 to $840{ }^{\circ} \mathrm{C}$ ) is due to residual silanol condensation $(4.5 \mathrm{wt} \%)$. This mass loss only occurred for the sample of F-MCM-41(3). The maximum of this stage occurring in the temperature $740{ }^{\circ} \mathrm{C}$. The presence of this mass loss in F-MCM-41(2) sample makes it different from the other samples, for which the complete removal of the surfactant and residual silanol groups had taken place already at a temperature range of 355-600 ${ }^{\circ} \mathrm{C}$.

As seen from the Fig. 8, the total mass losses that have occurred during the heating of the samples of F-MCM-41 mesoporous materials are about 41, 40 and $36 \mathrm{wt} \%$ for samples MCM-41(2), MCM-41(1) and MCM-41(3), respectively. Because the samples obtained from the filtrates are Al-MCM-41 aluminium sieves, larger total mass losses were observed for them compared to the silicon MCM-41 [18]. The thermal analysis showed that the 
FA-based F-MCM-41 mesoporous materials had a high thermal stability.

\section{Conclusions}

As demonstrated by the investigations carried out, TG is a very useful technique for determination of the temperature range for desorption of water, surfactant decomposition and silanol condensation for F-MCM-41 mesoporous materials obtained from coal FA as the new $\mathrm{Si}$ and $\mathrm{Al}$ sources. On the basis of the research conducted by means of TG analysis and nitrogen adsorption analyses one may state that

- The quite different percentage values of surfactant loss, surfactant decomposition ranges, and maxima, achieved for particular samples obtained from FA filtrates indicate different interactions between the associated surfactants due to the presence off $\mathrm{Si}$ and Al species (because the obtained mesoporous materials differed in the contents of $\mathrm{Si}$ and $\mathrm{Al}$ and associated ions (impurities), which were absent in the case of AlMCM-41 synthesis from the chemically pure sources of $\mathrm{Si}$ and $\mathrm{Al}$ ).

- The values of structure parameters (surface areas and pore diameters) confirm the mesoporous nature of the synthesized materials, despite lower than usual values observed for commercial Al-MCM-41 material synthesized from chemically pure Si sources.

- From amongst the samples tested, the smallest specific area was exhibited by the F-MCM-41(3) sample which contained most $\mathrm{Al}$ (the lowest $\mathrm{Si} / \mathrm{Al}$ ratio) and, at the same time, most impurities left from the FA extract. The least overall mass loss (36 wt $)$ and, at the same time, the least mass loss $(21 \mathrm{wt} \%)$ due to surfactant decomposition, as found for F-MCM-41(3), might indicate the fact that much less surfactant cations had combined with $\mathrm{Si}$ and $\mathrm{Al}$ species, compared to the remaining F-MCM-41 mesoporous materials. The maximum of surfactant removal for F-MCM-41(3) was also different from that for other samples (considerably higher).

Chemical composition of the FA extraction solution, and especially the contents of silicon and aluminium, plays a key role in the synthesis of mesoporous materials. The obtained results have shown a varying degree of dissolution of $\mathrm{Si}$ and $\mathrm{Al}$ from FA, depending on the FA composition and structure, which may provide a basis for the selection of FA for the production of mesoporous materials. The causes of the F-MCM-41 failing to form from a few filtrates, aside from the $\mathrm{Si}$ content and the $\mathrm{Si} / \mathrm{Al}$ ratio being too low, might also include the high $\mathrm{Na}$ content and the inadequate control of $\mathrm{pH}$, which is particularly important in the case of a large amount of $\mathrm{Na}$ in the initial gels. The results show that material properties of the calcined sample are dependent on the type of $\mathrm{FA}$ ( $\mathrm{Si} / \mathrm{Al}$ ratio in the extract). Because of the fact that FA, aside from a considerable amount of aluminosilicates, contains also some amount of different metal oxides, the formation of the mesoporous phase from FA is not as simple as from chemically pure reagents. On the basis of the research conducted, it was found that small amounts of impurities ( $\mathrm{Fe}, \mathrm{Ca}, \mathrm{K}, \mathrm{S}$ and $\mathrm{P}$ ) are both present inside the sample and are located in the channels of the MCM-41 formed. The presence of those impurities does not interfere, however, with the synthesis of the MCM-41 sieve. It should be underlined, at the same time, that the presence of metals (chiefly $\mathrm{Ca}$ and $\mathrm{Mg}$ originating from FA) is important, as they are likely to compensate the negative charge of the aluminosilicate lattice and take up cationic out-of-skeleton positions. The locations of such positions will determine the surface properties of obtained materials, which can be extremely useful in the application of the latter.

Although the porous structure parameters and other FA mesoporous material properties (e.g. thermal stability) are slightly inferior to commercial materials, yet they can be successfully used in many applications, e.g. as gaseous pollutant adsorbents. Similarly as their commercial counterparts, FA-synthesized mesoporous materials have the potential to be practically used as catalyst and sorbents, being useful mainly in separation technologies applicable in environmental protection.

Acknowledgements This study was carried out thanks to the support from the Project funded by a grant from Iceland, Liechtenstein and Norway through the EEA Financial Mechanism and the Norwegian Financial Mechanism (E031/T02/2008/02/85). The author gratefully acknowledges the same.

Open Access This article is distributed under the terms of the Creative Commons Attribution Noncommercial License which permits any noncommercial use, distribution, and reproduction in any medium, provided the original author(s) and source are credited.

\section{References}

1. Shigemoto N, Hayashi H, Miyaura K. Selective formation of Na$\mathrm{X}$ zeolite from fly ash by fusion with sodium hydroxide prior to hydrothermal reaction. J Mater Sci. 1993;28:4781-6.

2. Majchrzak-Kucęba I, Nowak W. Thermal analysis of fly ashbased zeolites. J Therm Anal Calorim. 2004;77:125-31.

3. Chang HL, Chun Ch, Aksay IA, Shih WH. Conversion of fly ash into mesoporous aluminosilicate. Ind Eng Chem Res. 1999;38: 973-7.

4. Kumar P, Mal N, Oumi Y, Yamana K, Sano T. Mesoporous materials prepared using coal fly ash as the silicon and aluminium source. J Mater Chem. 2001;11:3285-90. 
5. Hui KS, Chao CYH. Synthesis of MCM-41 from coal fly ash by a green approach: influence of synthesis $\mathrm{pH}$. J Hazard Mater. 2006;B137:1135-48.

6. Misran H, Sing R, Begum S, Yarmo MAJ. Processing of mesoporous silica materials (MCM-41) from coal fly ash. J Mater Process Technol. 2007;186:8-13.

7. Misran H, Ramesh S, Yarmo MA, Kamarudin RA. Non-hydrothermal synthesis of mesoporous materials using sodium silicate from coal fly ash. Mater Chem Phys. 2007;101:344-51.

8. Chandrasekar G, You KS, Ahn JW, Ahn WS. Synthesis of hexagonal and cubic mesoporous silica using power plant bottom ash. Microporous Mesoporous Mater. 2008;111:455-62.

9. Beck JS, Vartuli JC, Roth WJ, Leonowicz ME, Kresge CT, Schmitt KD, Chu CTW, Olsen DH, Sheppard EW, McCullen SB, Higgins JB, Schlenker JL. A new family of mesoporous molecular sieves prepared with liquid crystal templates. J Am Chem Soc. 1992;114:10835-43.

10. Barbosa MN, Araujo AS, Galvao LPFC, Silva EFB, Santos EFB, Luz GE, Fernandes VJ. Carbon dioxide adsorption over DIPA functionalized MCM-41 and SBA-15 molecular sieves. J Therm Anal Calorim. 2011. doi:10.1007/s1097301113988.

11. Bhagiyalakshmi M, Yun LJ, Anuradha R, Jang HT. Utilization of rice husk ash as silica source for the synthesis of mesoporous silicas and their application to $\mathrm{CO}_{2}$ adsorption through TREN/ TEPA grafting. J Hazard Mater. 2010;175:928-38.

12. Gaworek J, Kierys A, Gac W, Borówka A, Kusak R. Thermal degradation of CTAB in as-synthesized MCM-41. J Therm Anal Calorim. 2009;92:375-82.

13. Araujo SA, Jaroniec M. Thermogravimetric monitoring of the MCM-41 synthesis. Thermochim Acta. 2000;363:175-80.
14. Araujo SA, Ionashiro M, Fernandes VJJ Jr. Thermogravimetric investigations during the synthesis of silica-based MCM-41. J Therm Anal Calorim. 2001;64:801-5.

15. Souza MJB, Silva AOS, Aquino JMFB, Fernandes VJ Jr, Araujo AS. Thermal analysis applied to template removal from siliceous MCM-48 nanoporous material. J Therm Anal Calorim. 2005; 79:493-7.

16. Coutinho ACSLS, Quintella SA, Araujo AS, Barros JMF, Pedrosa AMG, Fernandes VJ Jr, Souza MJB. Thermogravimetry applied to characterization of SBA15 nanostructured material. J Therm Anal Calorim. 2007;87:457-61.

17. Souza LKC, Pardauil JJR, Zamian JR, Filho GNR, Costa CEF. Influence of the incorporated metal on template removal from MCM-41 type mesoporous materials. J Therm Anal Calorim. 2011. doi:10.1007/s1097301112951.

18. Xu R, Pang W, Yu J, Huo Q, Chen J. Chemistry of zeolites and related porous materials. Chichester: Wiley (Asia) Pte Ltd; 2007.

19. Kruk M, Jaroniec M, Sayari A. Adsorption study of surface and structural properties of MCM-41 materials of different pore sizes. J Phys Chem B. 1997;101:583-89.

20. Yang H, Deng Y, Du Ch, Jin S. Novel synthesis of ordered mesoporous materials Al-MCM-41 from natural bentonite. Appl Clay Sci. 2010;47:351-5.

21. Adjdir M, Ali-Dahmane T, Friedrich F, Scherer T, Weidler PG. The synthesis of Al-MCM-41 from Volclay-a low-cost Al and Si source. Appl Clay Sci. 2009;46:185-9.

22. Jansen JC, Stocker M, Karge HG, Weitkamp J. Advanced zeolite science and catalysis. Amsterdam: Elsevier; 1994. 